Session 3513

\title{
A Case Study in Stoichiometry Course Using Excel and Power Point Presentation
}

\author{
M. Hossein Hariri \\ Department of Chemical Engineering \\ Rose-Hulman Institute of Technology \\ Terre Haute, IN 47803
}

\begin{abstract}
Production of syngas from coal was considered as a case study project for the stoichiometry course. In this case study we showed the students how to divide a complex process such as above to smaller single units as the first step. The flowsheets of each single unit was drawn on a slide using Microsoft Power Point. Then we showed how to produce spreadsheets for the single units in an Excel workbook and link the spreadsheets together. With Power Point Presentation we could present the flowsheet of a single unit and switch to the corresponding Excel sheet for the calculations in a Windows 95 environment. The linkage of the spreadsheets are useful for parametric studies on the overall process.

\section{$\underline{\text { Introduction }}$}

This case study was assigned to sophomore students in order to reinforce the material they learn in the stoichiometry course. The case study problem involves the production of syngas from coal ${ }^{1}$. The syngas produced in this case study is intended to be used downstream in the production of methanol.

A case study of this sort takes a considerable amount of time and effort from students. In the past case studies were either not assigned to students in stoichiometry class or the assignment came late in the term. The result was, therefore, a marginal engagement of students. In order to improve the situation, we decided to assign the project right from the beginning of the course. The intent was that the students can work on parts of case study as they make progress in the course. This requires a careful sequence of materials to be assigned. We designed a proper sequence assisted by spreadsheet format and Presentation slides. Application of spreadsheets in sophomore year not only helps students to improve their computation skills, but also facilitates scale up of the process as well.

\section{Preparing the Case Study in an Assisted and Proper Sequence}

The detail of the process of production of syngas from coal, which was the subject of case study, is given in the reference ${ }^{1}$. In this process ground coal is fed to a gasifier to react with oxygen at high pressure and temperature (in the order of $6000 \mathrm{kPa}$ and $1000^{\circ} \mathrm{C}$ ) to make syngas containing carbon monoxide, hydrogen, carbon dioxide and water vapor in 
appreciable mole fractions and a number of other components in small percentages. The fly ash (the nonreactive minerals in the coal) in the syngas should be removed first. Syngas composition is then should be adjusted, through a series of operations, to satisfy the stoichiometric requirements associated with the production of methanol. These operations aim at increasing the hydrogen content of the syngas and decreasing the carbon dioxide. Also syngas should be desulfurized and dried before being used for methanol production.

To prepare the students to understand the problem the process flowsheet was divided into a number of small unit flowsheets, each drawn on a slide. Each slide was given an appropriate name, including Coal Gasification, Slag Removal, Syngas Upgrade, Cooling and Drying, Acid Gas Removal System, Sulfur Recovery and CO Cryogenic Separation. A number of slides in the beginning also explained coal as a fuel and the process of coal gasification.

In order to assist the students in calculations, spreadsheets were set up parallel to the slides. For each unit shown on a slide, a number of sheets were produced involving calculations specific to material and energy balances around that unit. Spreadsheets were named after the corresponding slide name. For example, there were four spreadsheets for material and energy balances around Coal Gasifier and were named Coal Gasification (1) to (4). In Windows 95 environment, one can easily switch between spreadsheet and slide presentation in order to interact between the unit flowsheets and the corresponding spreadsheet calculations.

\section{Project Assignment Process}

In the beginning of the course students were given the slides in order to learn about the process. A session in the beginning of the course was dedicated to learning the process and units flowsheets. The case study assignment was then given to the students in three parts. Students were required to submit their project reports for different parts. The assignment was divided into three parts to require the students to work on the project in a continuous fashion and not to postpone it to the final week of the term. This also enabled us to give exam questions on the materials in the case study.

To assist students to set up spreadsheets for calculations on different units, templates were e-mailed to them together with the statement of the assignments. These templates provide the set up of the sheets and some operating variables mentioned in the statement of the assignment and do not include any formulas or calculations. All sophomore students in the class owned laptop computers and the classrooms were equipped with networking facilities. This provided the e-mail connection between the instructor and the students inside and outside of the classroom. Moreover, the classrooms were equipped with the projection system that enabled the instructor to project his laptop on the big screen in order to view the slides as well as spreadsheets. 


\section{$\underline{\text { Project Reports }}$}

Students worked in groups of three. Each group was required to write three reports for the three parts of the assignment and submit them on the due dates for each part. The reports included the completed spreadsheets and the source and engineering description of the formulas in the key cells. In a number of cells the formulas were similar and could be copied and pasted from one cell. The cells of this sort were loosely defined as "nonkey cells". The format of the reports were kept simple to avoid spending time on unnecessary explanations.

\section{$\underline{\text { Students Performance }}$}

In the beginning and also for the report on part I of the case study assignment, students had difficulties in understanding the process of coal gasification, doing the calculations on the spreadsheet, especially where it involved solution of equations by iteration, and writing reports. All of the above improved considerably after the report on part I. Also including the case study material in the exams improved the participation of all of the students in a group in doing the project.

\section{Conclusions}

Stoichiometry is generally the first and probably the most important chemical engineering course. It is important to introduce the students to complex chemical engineering processes along with the regular class lectures and homework problems. Assignment of case studies in the beginning of the term serves this purpose. Doing a case study is a difficult assignment for sophomore students who are not familiar with the chemical engineering terminology and engineering procedures. Assisting them in different ways, such as described in this paper, enables them to take this difficult task and greatly benefit from it in their junior and senior years and probably future career.

\section{$\underline{\text { Reference }}$}

1. Felder, R.M. and Rousseau, R.W., Elementary Principles of Chemical Processes, $2^{\text {nd }}$ Edition (1986), Wiley, pp 571-576. 